\title{
Health-related quality of life of elderly with chronic obstructive pulmonary disease from selected government institutions
}

\section{Nor-Farahain Yahya ${ }^{1}$, Noraida Omar ${ }^{1,2^{\star}}$, Siti Nur' Asyura Adznam ${ }^{1,2}$, Ummi- $^{\prime}$ Nadira Daut ${ }^{3} \&$ Barakatun Nisak Mohd Yusof ${ }^{1}$}

${ }^{1}$ Department of Nutrition and Dietetics, Faculty of Medicine and Health Sciences, Universiti Putra Malaysia, Selangor, Malaysia; ${ }^{2}$ Malaysian Research Institute on Ageing (MyAgeing), Universiti Putra Malaysia, Selangor, Malaysia; ${ }^{3}$ Department of Medicine, Faculty of Medicine and Health Sciences, Universiti Putra Malaysia, Selangor, Malaysia

\begin{abstract}
Introduction: It is widely recognised that health-related quality of life (HRQOL) is impaired in chronic obstructive pulmonary disease (COPD) patients. Most previous studies were conducted among the younger adult population and there is limited information on the elderly population. This study aimed to determine the COPD assessment test (CAT) score in the elderly with COPD. Methods: This was a crosssectional study involving 140 elderly patients who had been diagnosed with COPD at two selected government institutions. Data on socio-demographic and health status were collected by interviewing patients and reviewing their medical records. The HRQOL was measured using CAT. The independence sample t-test and one-way ANOVA were conducted to compare the CAT scores with socio-demographic and health status. Results: The socio-demographic and health characteristics of the patients were as follows: majority (54\%) were aged 60-70 years, male (97\%), Malay $(59 \%)$, married $(75 \%)$, ex-smokers $(72 \%)$, had attained primary education $(48 \%)$, had co-morbidities (54\%), no history of hospitalisation or visits to the emergency department due to COPD (57\%), and were in moderate stage of airflow obstruction (53\%). The mean of CAT score was $21.87 \pm 6.85$ and the majority of the patients were classified as having worst symptoms of COPD (93\%) as they had high CAT score which was $\geq 10$. Conclusion: Majority of the patients in this study had high scores of CAT, which indicated poor HRQOL. Ex-smokers had higher scores compared to non-smokers. More attention need to be given to these subgroups in order to increase their quality of life.
\end{abstract}

Keywords: HRQOL, elderly, COPD, CAT score

\section{INTRODUCTION}

Aging is the process related to a variety of molecular and cellular damage that has accumulated as age increases
(Steves, Spector \& Jackson, 2012). This damage will lead to an increased risk of diseases as a result of the decline of physiological reserves (WHO, 2015). Chronic Obstructive Pulmonary

\footnotetext{
*Corresponding author: Noraida Omar

1. Department of Nutrition and Dietetics, Faculty of Medicine and Health Sciences, Universiti Putra Malaysia, Selangor, Malaysia

2. Malaysian Research Institute on Ageing (MyAgeing), Universiti Putra Malaysia, Selangor, Malaysia. Tel: (6) (03) 89472463; Fax: (6) (03) 89426769; E-mail: noraidaomar@upm.edu.my doi: https://doi.org/10.31246/mjn-2018-0162
} 
Disease (COPD) is a common disease among elderly, characterised by a slow progressive obstruction of the airway leading to the interference of normal breathing (WHO, 2018).

According to Global Burden of Disease Study, about 174 million cases of COPD were reported in 2015, which increased to 251 million in 2016 (WHO, 2018). The increasing number of COPD cases makes it a leading cause of mortality and morbidity in the world (Rabe \& Watz, 2017). Apart from that, COPD is classified as one of the top ten diseases causing a high burden to patient's life (Institute for Health Metrics and Evaluation, 2010). Cough, sputum production and shortness of breath are the main causes of the high burden, resulting in a decline of the healthrelated quality of life (HRQOL) (Martin et al., 2008). HRQOL is a subjective evaluation of an individual's or a group's perceived physical and mental health over time. It goes beyond direct measures of population health, life expectancy, and causes of death, and focuses on the impact health status has on quality of life (CDC, 2016).

HRQOL can be measured using generic and disease-specific instruments. The generic instrument covers a broader view of health while the disease-specific instrument concentrates on symptoms and function impairments related to COPD (Jones, 2013). The diseasespecific instrument was commonly used to measure HRQOL in COPD patients as it is more sensitive toward changes in the impact of the disease (Glaab, Vogelmeier \& Buhl, 2010).

Impact of COPD on HRQOL has been well established in many countries (Agrawal, Joshi \& Jain, 2015; Kim et al., 2013; Sundh et al., 2015). In Malaysia, a study that investigated HRQOL in COPD patients showed that lung function was related to HRQOL (Draman et al., 2013). An earlier local study also found that ethnicity, marital status, educational level, economic status, smoking and severity of the disease was related to HRQOL (Maria et al., 2010). However, most of the studies were conducted among the adult population and used the generic questionnaire to assess HRQOL.

HRQOL is important in managing COPD whether in primary or secondary health care (Arne et al., 2009). The Global Initiative for Chronic Obstructive Lung Disease (GOLD) recommended an assessment on the impact of the disease toward patients as part of COPD assessment (GOLD, 2018). Studies to determine HRQOL among the elderly with COPD are therefore indicated. The main objective of the present study was to determine the COPD assessment test (CAT) score in elderly patients with COPD while the specific objective was to compare CAT score with the sociodemographic and health status of the patients.

\section{MATERIALS AND METHODS}

\section{Study design}

In this cross-sectional study, 140 elderly patients with COPD were recruited from the Respiratory Clinic of Institute of Respiratory Medicine and the Serdang Hospital. The data collection was undertaken from August 2017 to January 2018. Those included were aged $\geq 60$ years, diagnosed with COPD, Malaysian citizens and able to stand properly without aid.

The number of patients who were involved in this study was estimated using the two proportion formula as below:

$$
\begin{aligned}
& \mathrm{n}=\frac{\mathrm{Z} 21-\alpha / 2[\mathrm{P} 1(1-\mathrm{P} 1)+\mathrm{P} 2(1-\mathrm{P} 2)]}{\mathrm{d} 2} \\
& \mathrm{n}=\frac{1.962[0.96(1-0.96)+0.051(1-0.051)]}{0.052} \\
& \mathrm{n}=133 \text { patients } \\
& \mathrm{n}=\text { sample size } \\
& \mathrm{Z} 1-\alpha / 2=\mathrm{z} \text { score at } 1-\alpha / 2 \text { confidence } \\
& \text { level }(\mathrm{Z} 1-\alpha / 2=1.96)
\end{aligned}
$$


$\mathrm{P} 1$ = prevalence for non-COPD group

$(\mathrm{P} 1=0.96)$ (Loh et al., 2016)

$\mathrm{P} 2=$ prevalence for COPD group

$(\mathrm{P} 2=0.051)($ Lim et al., 2015)

$\mathrm{d} 2=$ desire precision $(\mathrm{d}=0.05)$

Based on the calculation, at least 133 patients were required for this study. Using convenience sampling, all elderly patients with COPD who were available during data collection period were screened based on the inclusion criteria. About 197 patients met the criteria but only 140 of them agreed to participate in the study.

Permission to conduct data collection at the Institute of Respiratory Medicine and the Serdang Hospital was obtained from both institutions. Ethical approval was granted by the Ethics Committee for Research Involving Human Subjects of Universiti Putra Malaysia (JKEUPM) and the Medical Research \& Ethics Committee (MREC) with registration no. NNMR-17-589-34392. A written informed consent was obtained from the patients. If patients were unable to respond due to language barrier, the primary care-giver was appointed as the proxy respondent for the questionnaire and the interview.

\section{Measurements}

This study consisted of three parts, namely socio-demographic, health status and HRQOL. An intervieweradministered structured questionnaire was used for the socio-demographic and HRQOL parts, while the health status was determined using both interview and a review patient's medical record.

\section{Socio-demographic}

The socio-demographic data that was collected included the age, sex, race, educational level and marital status of the patient. In addition, their smoking habits were recorded based on their admission.

\section{Health status}

Data on co-morbidities, history of hospitalisation or emergency department due to the COPD and severity of airflow obstruction were obtained from the medical records of the patients. For comorbidities, this study focused on the diseases that are commonly observed in COPD patients such as cardiovascular disease, type 2 diabetes mellitus, chronic kidney disease and hypertension. The history of hospitalisation or visits to the visits to the emergency department due to COPD in previous one year was recorded. The severity of airflow obstruction was assessed using the spirometry test and was classified according to forced expiratory volume in one second $\left(\mathrm{FEV}_{1}\right)$ value: GOLD 1 (Mild), $\mathrm{FEV}_{1} \geq 80 \%$ predicted; GOLD 2 (Moderate), $50 \% \leq \mathrm{FEV}_{1}<80 \%$ predicted; GOLD 3 (Severe), 30\% $\leq \mathrm{FEV}_{1}<50 \%$ predicted; GOLD 4 (Very severe), $\mathrm{FEV}_{1}<$ $30 \%$ predicted (GOLD, 2018).

\section{Health-related quality of life}

CAT is a disease-specific instrument that was used in this study to measure HRQOL. This instrument was selected as it has fewer items and is therefore less time consuming and more convenient for clinical application (GOLD, 2018). Besides that, it is a validated questionnaire for use with COPD patients (Jones et al., 2009). There are eight questions in CAT covering cough, phlegm, chest tightness, breathlessness when going up an elevation (e.g. hills / stairs), activity limitation at home, self-confidence about leaving home, sleep and energy. The patients needed to answer based on a 6 Likert scale, 0 describing the best state or condition and 5 the worst. The patients were required to choose one answer for each question. The scores of the individual questions were added to obtain the total score. The total score ranged from $0-40$ indicating the best to the worst condition (Jones et 
Table 1. Demographic and health characteristics of the patients with COPD $(n=140)$

\begin{tabular}{|c|c|c|}
\hline Characteristics & $n(\%)$ & Mean $\pm S D$ \\
\hline \multicolumn{3}{|l|}{ Socio-demographic } \\
\hline Age (years) & & $70 \pm 7$ \\
\hline $60-70$ years & $76(54)$ & \\
\hline$>70$ years & $64(46)$ & \\
\hline \multicolumn{3}{|l|}{ Gender } \\
\hline Male & $136(97)$ & \\
\hline Female & $4(3)$ & \\
\hline \multicolumn{3}{|l|}{ Race } \\
\hline Malay & $82(59)$ & \\
\hline Chinese & $37(26)$ & \\
\hline Indian & $21(15)$ & \\
\hline \multicolumn{3}{|l|}{ Educational level } \\
\hline None & $16(11)$ & \\
\hline Primary schooling & $67(48)$ & \\
\hline Secondary schooling & $42(30)$ & \\
\hline Tertiary schooling & $15(11)$ & \\
\hline \multicolumn{3}{|l|}{ Marital status } \\
\hline Single & $8(6)$ & \\
\hline Married & $105(75)$ & \\
\hline Divorced/Widowed & 27 (19) & \\
\hline \multicolumn{3}{|l|}{ Smoking habits } \\
\hline Smoker & $30(22)$ & \\
\hline Ex-smoker & $101(72)$ & \\
\hline Non-smoker & $9(6)$ & \\
\hline \multicolumn{3}{|l|}{ Amount of cigarettes / day $^{\dagger}$} \\
\hline Less than 1 pack (20 cigarettes / pack) & $27(90)$ & \\
\hline 1 pack (20 cigarettes / pack) & $3(10)$ & \\
\hline More than 1 pack (20 cigarettes / pack) & $0(0)$ & \\
\hline \multicolumn{3}{|l|}{ Health status } \\
\hline \multicolumn{3}{|l|}{ Co-morbidities } \\
\hline Not present with co-morbidities & $64(46)$ & \\
\hline Present with co-morbidities & $76(54)$ & \\
\hline Hypertension & $56(74)$ & \\
\hline Diabetes Mellitus & $29(38)$ & \\
\hline Heart disease & $18(24)$ & \\
\hline Dyslipidaemia & $14(18)$ & \\
\hline Chronic Kidney Disease & $6(8)$ & \\
\hline \multicolumn{3}{|c|}{$\begin{array}{l}\text { History of hospitalization or visits to emergency department due } \\
\text { to COPD }\end{array}$} \\
\hline None & $79(57)$ & \\
\hline At least one episode & $38(27)$ & \\
\hline More than one episode & $23(16)$ & \\
\hline \multicolumn{3}{|l|}{ Severity of COPD } \\
\hline Mild (FEV $\geq 80 \%$ predicted) & $14(13)$ & \\
\hline Moderate $(50 \% \leq \mathrm{FEV}<80 \%$ predicted $)$ & $58(53)$ & \\
\hline Severe $(30 \% \leq \mathrm{FEV}<50 \%$ predicted $)$ & $34(31)$ & \\
\hline Very severe $\left(\mathrm{FEV}_{1}<30 \%\right.$ predicted $)$ & $3(3)$ & \\
\hline \multicolumn{3}{|l|}{ Health-related quality of life } \\
\hline Total score of CAT & & $21.87 \pm 6.85$ \\
\hline Less symptoms $(<10)$ & $10(7)$ & \\
\hline More symptoms $(\geq 10)$ & $130(93)$ & \\
\hline
\end{tabular}

${ }^{\dagger} N=30$, based on number of smokers

${ }^{\ddagger} N=109$, missing data due to no latest spirometry test for the past one year 
Table 2. Mean of CAT score by socio-demographic and health status among elderly with COPD $(N=140)$

\begin{tabular}{|c|c|c|c|c|}
\hline \multirow{2}{*}{ Variables } & \multirow[b]{2}{*}{$n$} & \multicolumn{3}{|c|}{ CAT score } \\
\hline & & Mean $\pm S D$ & $t / F$ & $p$ \\
\hline \multicolumn{5}{|l|}{ Socio-demographic } \\
\hline \multicolumn{5}{|l|}{ Age (years) } \\
\hline $60-70$ & 76 & $21.45 \pm 6.78$ & 0.062 & 0.427 \\
\hline$>70$ & 64 & $22.38 \pm 6.95$ & & \\
\hline \multicolumn{5}{|l|}{ Sex } \\
\hline Male & 136 & $21.79 \pm 6.92$ & -0.852 & 0.396 \\
\hline Female & 4 & $24.75 \pm 3.30$ & & \\
\hline \multicolumn{5}{|l|}{ Race } \\
\hline Malay & 82 & $21.96 \pm 7.13$ & 0.351 & 0.705 \\
\hline Chinese & 37 & $22.30 \pm 6.60$ & & \\
\hline Indian & 21 & $20.76 \pm 6.36$ & & \\
\hline \multicolumn{5}{|l|}{ Educational level } \\
\hline None & 16 & $22.19 \pm 7.28$ & 0.815 & 0.488 \\
\hline Primary schooling & 67 & $22.57 \pm 6.94$ & & \\
\hline Secondary schooling & 42 & $21.43 \pm 6.71$ & & \\
\hline Tertiary schooling & 15 & $19.67 \pm 6.47$ & & \\
\hline \multicolumn{5}{|l|}{ Marital status } \\
\hline Single/Divorced/Widowed & 35 & $22.37 \pm 5.69$ & 0.497 & 0.620 \\
\hline Married & 105 & $21.70 \pm 7.21$ & & \\
\hline \multicolumn{5}{|l|}{ Smoking habits } \\
\hline Smoker & 30 & $21.90 \pm 5.72$ & 3.300 & $0.040^{*}$ \\
\hline Ex-smoker & 101 & $22.36 \pm 7.17^{\mathrm{a}}$ & & \\
\hline Non-smoker & 9 & $16.33 \pm 4.06^{\mathrm{a}}$ & & \\
\hline \multicolumn{5}{|l|}{ Health status } \\
\hline \multicolumn{5}{|l|}{ Co-morbidities } \\
\hline Not present & 64 & $22.03 \pm 6.48$ & 0.252 & 0.801 \\
\hline Present & 76 & $21.71 \pm 7.19$ & & \\
\hline \multicolumn{5}{|l|}{$\begin{array}{l}\text { History of hospitalization or visit } \\
\text { emergency department due to COPD }\end{array}$} \\
\hline None & 79 & $20.77 \pm 6.80$ & 2.883 & 0.059 \\
\hline At least one episode & 38 & $22.63 \pm 7.21$ & & \\
\hline More than one episode & 23 & $24.39 \pm 5.76$ & & \\
\hline \multicolumn{5}{|l|}{ Severity of airflow obstruction ${ }^{\dagger}$} \\
\hline Mild (FEV $1 \geq 80 \%$ predicted) & 14 & $20.50 \pm 7.89$ & 0.289 & 0.833 \\
\hline Moderate $\left(50 \% \leq \mathrm{FEV}_{1}<80 \%\right.$ predicted $)$ & 58 & $22.38 \pm 7.46$ & & \\
\hline Severe $\left(30 \% \leq \mathrm{FEV}_{1}<50 \%\right.$ predicted & 34 & $22.47 \pm 5.75$ & & \\
\hline Very severe $\left(\mathrm{FEV}_{1}<30 \%\right.$ predicted $)$ & 3 & $22.67 \pm 14.64$ & & \\
\hline
\end{tabular}

Identical superscript letters indicate significant difference

${ }^{*} p<0.050$

${ }^{\dagger} n=109$, missing data due to no latest spirometry test for the past one year 
al., 2009). Based on GOLD (2018), the total scores of CAT are classified based on the presence of symptoms, namely, few symptoms $(<10)$ or more symptoms $(\geq 10)$.

\section{Statistical Analysis}

The data collected were analysed using the Statistical Package for Social Sciences (SPSS) version 22 software. Descriptive analysis was used to report the frequency, percentage, mean and standard deviation. The independentsamples t-test and one-way analysis of variance (ANOVA) with the post hoc Turkey test were performed to compare the CAT score with socio-demographic and health status. The level of significance of the $p$-value was set at 0.05 for all the statistical tests.

\section{RESULTS}

The socio-demographic and health characteristics of the patients are shown in Table 1. The mean score for CAT was $21.87 \pm 6.85$ with a range of $4-36$. The majority of the patients $(93 \%)$ had more symptoms of COPD as they had the total score of $\mathrm{CAT} \geq 10$.

Table 2 shows the mean of CAT score by socio-demographic and health status. The patients who were older (age $>70$ years), female, Chinese, single and with primary schooling had a higher CAT scores compared to others for these characteristics, but no significant difference was found. In terms of the smoking habit, ex-smokers had a significantly higher CAT score than to non-smokers $(p<0.05)$. However, there were no differences between non-smokers and smokers, as well as between smokers and ex-smokers.

Patients without co-morbidities surprisingly had a worse CAT score than patients presented with co-morbidities, but with no significant difference. The patients who had a history of hospitalisation or visits emergency department due to the COPD had a higher CAT score than those who did not. The patients who had very severe stage of airflow obstruction also showed similar results. But differences were not significant for both.

\section{DISCUSSION}

The mean CAT score for this study was $21.87 \pm 6.85$, which is almost similar to the findings of previous studies in a developed country, the United Kingdom (Dodd et al., 2012; Kelly et al., 2012). The studies by Dodd et al. (2012) and Kelly et al. (2012) reported that the mean of CAT score for their studies were $22.1 \pm 7.5$ and 23.1 \pm 8.2 , respectively. By contrast, a study in Japan found that the mean CAT for their elderly patients (65-74 years, $5 \pm 8$; $75-84$ years, $8 \pm 8$; > 85 years, $9 \pm 8.5$ ) was better compared to that of the present study and the studies done in the United Kingdom (Kobayashi et al., 2014). The difference might be because the patients from the Japan study had COPD explained to them at the hospital (Kobayashi et al., 2014). Thus, their better knowledge of the disease might have helped them achieve a higher quality of life.

This study found that $93 \%$ of the patients had high CAT scores $(\geq 10)$ that indicated worse symptoms of COPD. This proportion was higher than the $80 \%$ found in a local study in Kelantan (Draman et al., 2013). A study conducted in South Korea indicated similar results, which $69 \%$ of their patients had high CAT scores (Kim et al., 2013).

The finding of no significant differences for CAT score for age is consistent with that obtained by Sundh et al. (2011). This could be because the age of the elderly patients in this study did not vary greatly and hence the CAT score may not vary much as well. No significant differences were found in our study in CAT score for gender, race, educational level and marital status which is inconsistent with the findings of Maria et al. (2010). This might be 
explained by the small number of female patients in this study. Apart from that, HRQOL may be influenced by other factors which were not being examined in this study such as the body mass index, patient's occupation and income.

Our finding that ex-smokers had poor HRQOL compared to non-smokers is in agreement with that of another study by Sundh et al. (2011). As smoking is a risk factor for COPD, it may explain why their lung function was worse compared to the others, leading to their poor quality of life (GOLD, 2018). Thomsen et al. (2013) found that non-smokers with COPD had less symptoms and less airflow obstruction compared to COPD patients with smoking history.

The poor quality of life is more common in COPD patients who had co-morbidities (Sundh et al., 2011). HRQOL became worse as the number of co-morbidities increased (Wacker et al., 2016). This could be the result of them seeking for health care more frequently compared to patients with COPD only. However, the present study found no significant difference of HRQOL between patients with and without co-morbidities. This could be due to under reporting of co-morbidities, since our study selected only five common diseases for this purpose. The patients were considered as not having co-morbidities, when they did not suffer from any of these.

The patients who were frequently admitted to hospital due to COPD had worse HRQOL is consonant with the findings of Jones et al. (2011). A higher number of hospital admissions was closely related with poor HRQOL (Hong et al., 2015). They were admitted to hospital more frequently as their quality of life decreased. Our finding that quality of life worsened as the severity of the airflow obstruction increased in patients is consistent with that of other studies (Jones et al., 2011; Agrawal et al., 2015; Hong et al., 2015; Wacker et al., 2016).

Other than factors discussed above, poor nutritional status might be another contributor of poor HRQOL. COPD and elderly patients are usually presented with poor nutritional status (King, Cordova \& Scharf, 2008; Saka et al., 2010). As a result of this, COPD patients experienced a decline in exercise ability, which then in turn contributed to poor HRQOL (Mostert et al., 2000).

Use of a validated HRQOL questionnaire is the strength of the study. The CAT questionnaire has been used in many studies and validated in several countries. It is the latest diseasespecific questionnaire that is used to determine HRQOL in COPD patients. A limitation of this study is that it was dominated by male patients. Apart from that, this study used secondary data from medical records for health status information like co-morbidities, history of hospitalisation or visits to the emergency department due to acute exacerbation and results of the spirometry tests. Thus, data may have been incomplete and insufficient. This could have interfered with the results of study. Besides that, multiple logistic regression could not be performed to predict factors that contributed to the HRQOL, as data for HRQOL was not equally distributed. Future studies should be larger to explore the socio-demographic and health status contributions towards HRQOL.

\section{CONCLUSION}

COPD does indeed have a negative impact on elderly patients especially among former smokers as they presented with higher CAT score compared to others. Healthcare professionals should pay closer attention to this group and implement suitable interventions such as providing pulmonary rehabilitation and advice on smoking cessation. Interventions should be carried out early to increase their quality of life and delay the disease progress. 


\section{Acknowledgements}

The authors would like to thank all patients who generously shared their time and experience for the study, and to Universiti Putra Malaysia for providing research funding under Putra GrantPutra Young Initiative (IPM) (9517400).

\section{Author's contribution}

N-FY, researcher, devised and conducted the study, data analysis and interpretation, prepared the draft of the manuscript; NO, principal investigator, assisted in study and result's interpretation, reviewed the manuscript; SNAA, assisted in the study, the interpretation of the results, and reviewed the manuscript; UND, assisted in study and result's interpretation, reviewed the manuscript; BNMY, assisted in the study, the interpretation of results and reviewed the manuscript.

\section{Conflict of interest}

The authors have no conflicts of interest to declare.

\section{References}

Agrawal SR, Joshi R \& Jain A (2015). Correlation of severity of chronic obstructive pulmonary disease with health-related quality of life and six-minute walk test in a rural hospital of central India. Lung India 32(3):233-240.

Arne M, Janson C, Janson S, Boman G, Lindqvist U, Berne C \& Emtner M (2009). Physical activity and quality of life in subjects with chronic disease: Chronic obstructive pulmonary disease compared with rheumatoid arthritis and diabetes mellitus. Scandinavian Journal of Primary Health Care 27(3):141-147.

Centers for Disease Control and Prevention (CDC) (2016). In: HRQOL concepts. From https:// www.cdc.gov/hrqol/concept.htm. [Retrieved October 15 2018].

Dodd JW, Marns PL, Clark AL, Ingram KA, Fowler RP, Canavan JL, Patel MS, Kon SSC, Hopkinson NS, Polkey MI, Jones PW \& Man WDC (2012). The COPD Assessment Test (CAT): Shortand medium-term response to pulmonary rehabilitation. COPD: Journal of Chronic Obstructive Pulmonary Disease 9(4):390-394.

Draman N, Hasnan HM, Mohamed WM \& Jaeb MZM (2013). The association of the COPD Assessment Test (CAT) score with chronic obstructive lung disease (GOLD) grade among Chronic Obstructive Pulmonary Disease (COPD) outpatients in the north east of Peninsular Malaysia. International Journal of Collaborative Research on Internal Medicine \& Public Health 5(9):596-607.
Glaab T, Vogelmeier C \& Buhl R (2010). Outcome measures in chronic obstructive pulmonary disease (COPD): strengths and limitations. Respiratory Research 11:79.

Global Initiative for Chronic Obstructive Lung Disease (GOLD) (2018). Global Strategy for the Diagnosis, Management, and Prevention of Chronic Obstructive Pulmonary Disease. 2018 Report. From https://goldcopd.org/wpcontent/uploads / 2017 / 11/GOLD-2018-v6.0FINAL-revised-20-Nov_WMS.pdf. [Retrieved September 1 2018].

Hong JY, Kim SY, Chung KS, Kim EY, Jung JY, Park MS, Kang YA, Kim SK, Chang J \& Kim YS (2015). Factors associated with the quality of life of Korean COPD patients as measured by the EQ-5D. Quality of Life Research 24(10):2549-2558.

Institute for Health Metrics and Evaluation (2010). The Global Burden of Disease: Generating Evidence, Guiding, Policy. World Bank, Washington DC.

Jones PW (2013). Health status measurement. Outcomes in Clinical Trials: European Respiratory Monograph 62:13.

Jones PW, Brusselle G, Dal Negro RW, Ferrer M, Kardos P, Levy M, Perez T, Soler-Cataluna JJ, Van der Molen T, Adamek L \& Banik N (2011). Health-related quality of life in patients by COPD severity within primary care in Europe. Respiratory Medicine 105(1):57-66.

Jones PW, Harding G, Berry P, Wiklund I, Chen WH \& Leidy NK (2009). Development and first validation of the COPD Assessment Test. European Respiratory Journal 34(3):648-654.

Kelly JL, Bamsey O, Smith C, Lord VM, Shrikrishna D, Jones PW, Polkey MI \& Hopkinson NS (2012). Health status assessment in routine clinical practice: The chronic obstructive pulmonary disease assessment test score in outpatients. Respiration 84(3):193-199.

King DA, Cordova F \& Scharf SM (2008). Nutritional Aspects of Chronic Obstructive Pulmonary Disease. Proceedings of the American Thoracic Society 5(4):519-523.

Kim S, Oh J, Kim YI, Ban HJ, Kwon YS, Oh IJ, Kim KS, Kim YC \& Lim SC (2013). Differences in classification of COPD group using COPD assessment test (CAT) or modified Medical Research Council (mMRC) dyspnea scores : a cross-sectional analyses. BMC Pulmonary Medicine 13(1):35. 
Kobayashi S, Yanai M, Hanagama M, \& Yamanda S (2014). Burden of chronic obstructive pulmonary disease in the elderly population. Respir Investig 52(5):296-301.

Lim S, Lam DCL, Muttalif AR, Yunus F, Wongtim S, Lan LTT, Shetty V, Chu R, Zheng J, Perng DW \& de Guia T (2015). Impact of chronic obstructive pulmonary disease (COPD) in the Asia Pacific region: the EPIC Asia population based survey. Asia Pacific Family Medicine 14(1):4.

Loh LC, Rashid A, Siti S, Gnatiuc L, Patel JH \& Burney P (2016). Low prevalence of obstructive lung disease in a suburban population of Malaysia: A BOLD collaborative study. Respirology 21(6):1055-1061.

Maria J, Aslinda CM, Nurul Ain AR \& Fatim TM (2010). Health-related quality of life of COPD patients attending outpatient clinic at Institute of Respiratory Medicine, Kuala Lumpur, Malaysia. International Medical Journal 9(1):913.

Martín A, Moro JM, Izquierdo JL, Gobartt E \& de Lucas P (2008). Health-related quality of life in outpatients with COPD in daily practice: The VICE Spanish Study. International Journal of COPD 3(4):683-692.

Mostert R, Goris A, Weling-Scheepers C, Wouters EFM \& Schols AMWJ (2000). Tissue depletion and health related quality of life in patients with chronic obstructive pulmonary disease. Respiratory Medicine 94:859-867.

Rabe KF \& Watz H (2017). Chronic Obstructive Pulmonary Disease. The Lancet 389 (10082):P1931-1940.

Saka B, Kaya O, Ozturk GB, Erten N \& Karan MA (2010). Malnutrition in the elderly and its relationship with other geriatric syndromes. Clinical Nutrition 29(6):745-748.
Steves CJ, Spector TD \& Jackson SH (2012). Ageing, genes, environment and epigenetics: what twin studies tell us now, and in the future. Age and Ageing 41(5):581-586.

Sundh J, Johansson G, Larsson K, Lindén A, Löfdahl CG, Janson C \& Sandström T (2015). Comorbidity and health-related quality of life in patients with severe chronic obstructive pulmonary disease attending Swedish secondary care units. International Journal of Chronic Obstructive Pulmonary Disease 10:173-183.

Sundh J, Ställberg B, Lisspers K, Montgomery SM \& Janson C (2011). Co-morbidity, body mass index and quality of life in COPD using the Clinical COPD Questionnaire. COPD: Journal of Chronic Obstructive Pulmonary Disease Disease 8(3):173-181.

Thomsen M, Nordestgaard BG, Vestbo J \& Lange $P$ (2013). Characteristics and outcomes of chronic obstructive pulmonary disease in never smokers in Denmark: a prospective population study. The Lancet Respiratory Medicine 1(7):543-50.

Wacker ME, Jörres RA, Karch A, Wilke S, Heinrich J, Karrasch S, Koch A, Schulz H, Watz H, Leidl R, Vogelmeier C \& Holle R (2016). Assessing health-related quality of life in COPD : comparing generic and disease-specific instruments with focus on comorbidities. BMC Pulmonary Medicine 16(1):1-11.

WHO (2015). World report on ageing and health. World Health Organization, Geneva.

WHO (2018). In: Chronic Respiratory Disease: Chronic Obstructive Pulmonary Disease. From http://www.who.int/respiratory/copd/en/. [Retrieved October 12 2018]. 